\title{
The Importance of Broadband for Socio-Economic Development: A Perspective from Rural Australia
}

\author{
Julie Freeman \\ Deakin University \\ J ulie.Freeman@deakin.edu.au
}

\section{Sora Park}

University of Canberra

\section{Catherine Middleton}

Ryerson University

\section{Matthew Allen}

Deakin University

\section{Abstract}

Advanced connectivity offers rural communities prospects for socio-economic development. Despite Australia's national broadband infrastructure plans, inferior availability and quality of rural Internet connections remain persistent issues. This article examines theimpact of limited connectivity on rural socio-economic opportunities, drawing from the views of twelve citizens from the Boorowa local government area in New South Wales. The available fixed wireless and satellite connections in Boorowa are slow and unreliable, and remote regions in the municipality are still without any Internet access. Participants identified four key areas in their everyday lives that are impacted by insufficient connectivity: business development, education, emergency communication, and health. Rural citizens often already face challenges in these areas, and infrastructure advancements in urban spaces can exacerbate rural-urban disparities. Participants' comments demonstrated apprehension that failure to improve connectivity would result in adverse long-term consequences for the municipality. This article suggests that current broadband policy frameworks require strategic adaptations to account for the socio-economic and geographic contexts of rural communities. In order to narrow Australia's rural-urban digital divide, infrastructure developments should be prioritised in the most underserved regions.

Keywords: Rural connectivity; National Broadband Network; socio-economic development; policy; digital divide; digital inclusion

\section{Introduction}

Access to reliable and fast digital connectivity is a perennial problem in rural Australia despite large-scale investments and infrastructure developments under various iterations of the National Broadband Network (NBN) and several specific-purpose rural access programs in earlier years (Middleton \& Park, 2014; Alizadeh, 2013; Tiwari, Lane \& Alam, 2015). The NBN was once heralded as offering rural communities prospects for development and inclusion in the digital economy by overcoming some of the disadvantages associated with physical distances (Department of Broadband, Communications and the Digital Economy, 2011). While slow and uneven network rollout (Middleton \& Park, 2014) was to be expected with such a large-scale complex project, ongoing disparities in broadband access continue to jeopardise rural socio-economic opportunities (Alizadeh, 2013).

This article offers evidence of the impacts of limited connectivity (including fixed-line, mobile and satellite Internet) on a rural community drawn from discussions with twelve citizens from the Boorowa local government area in New South Wales. The availability and quality of Internet access in Boorowa significantly lags behind urban centres. Access in this region suffers from variable signal strengths, ongoing latency issues, significant costs, and fails to support high-bandwidth services. Additionally, there are especially remote areas in the municipality 
that still lack any Internet access. Participants identified four key areas in their community that are affected by limited connectivity: business development, education, emergency communication, and health.

Digital connectivity has been recognised to be a driver of rural socio-economic prosperity (Townsend, Sathiaseelan, Fairhurst \&Wallace, 2013; Prieger, 2013; Katz \& Suter, 2009). The Internet is increasingly becoming a prerequisite to complete everyday tasks, but the apparent lack of urgency in extending effective broadband connectivity to rural Australia is reinforcing and extending existing rural-urban discrepancies (Alizadeh, 2013). The risk in this situation is that current disparities faced by rural communities are likely to be exacerbated as urban spaces receive advanced connectivity, and rural citizens become less able, relatively speaking, to take advantage of digital business, learning, health and safety opportunities. This article suggests that the conditions of rurality require greater consideration in NBN developments to account for communities' socio-economic and geographical contexts. If Australia is to narrow its ruralurban digital divide, then underserved rural regions should be prioritised for government investment in broadband infrastructure developments, as they were in the period before the NBN was first commissioned.

\section{Literature Review}

Advanced connectivity facilitates positive economic effects, digital citizenship practices and increased societal engagement (Prieger, 2013). Broadband has widely been attributed to fostering economic growth through improved business productivity, building human capital through online education and digital civic engagement, creating opportunities for knowledgebased telework, as well as providing greater access to essential services such as tele-healthcare (Griffith, Heydon, Lamb, Lefort, Taylor, Trotter \&Wark, 2013; Townsend et al., 2013; Prieger, 2013; Steele \& Lo, 2013). However, the activities pursued online are fundamentally shaped by the availability and quality of Internet connections, and those with broadband engage in more online activities (Hale, Cotton, Drentea \& Goldner, 2010).

In rural areas, distance to major services and low population densities increase the costs of building network infrastructure. Areas with small and geographically dispersed populations provide low demand and high financial outlay (Tiwari et al., 2015; Eardley, Bruce \& Goggin, 2009). While Australia has a range of regional telecommunications policies, rural areas continue to suffer from lower Internet penetration, poorer broadband connectivity, and higher costs for these services (Regional Telecommunications Independent Review Committee, 2015). Internet and broadband penetration decrease as remoteness increases. In very remote areas, only $41.4 \%$ of the population have broadband and $49.6 \%$ have Internet access at home. In contrast, the figures for major cities are $70.8 \%$ and $77.3 \%$, respectively (ABS, 2013).

Despite efforts to narrow the digital divide between rural and urban areas, this gap has not been significantly reduced and the effects of the gap are exacerbated by rural areas' overall lower educational and income levels as well as aging populations (Park, Freeman, Middleton, Allen, Eckermann \& Everson, 2015). Moreover, absence of rural competition diminishes the provision of innovative services and prospects for reduced prices, with limited consumer choice resulting in increased cost to access inferior infrastructure (Eardley et al., 2009). As potential rural users are often already financially disadvantaged, additional costs for Internet access may prove to be unnecessary expenses (Notara, 2011).

In addition to poor availability, the quality and reliability of rural broadband is inferior to metropolitan areas, with many communities "severely limited" (Department of Communications, 2013a, p4). Rural broadband access under NBN plans will predominantly be achieved through fixed wireless and satellite technologies, rather than fibre-optic cabling. Both fixed wireless and satellite connections offer significantly slower speeds, particularly for uploading, than fixed-line broadband (Middleton \& Park, 2014; Tiwari et al., 2015; Martin \& Rice, 2012). The first and foremost issue therefore is uneven access to quality Internet services in rural areas. 
Rural areas already face socio-economic challenges, such as limited access to healthcare and education facilities as well as reduced opportunities for business expansion (J ones, Cardoso, Hüttner, Oliveira, dos Santos, Lopes \& Russomano, 2012; Townsend et al., 2013). Rural infrastructure investments have demonstrated positive socio-economic impacts and increases in productivity and participation (Katz \& Suter, 2009). For example, communities with highquality broadband are more economically competitive (Townsend et al., 2013; Alizadeh, 2013) and, for businesses, the Internet has become a requirement for transactional and transformative change, improved performance and new opportunities (Mazzarol, 2015; Townsend et al., 2013). Mazzarol (2015) argues that for small and medium enterprises the decision to engage in the digital economy is no longer an option. The concern here then is what happens to rural businesses that are willing but unable to digitally participate.

Beyond business and economic prospects, advanced connectivity enables essential rural services (Townsend et al., 2013). In the area of healthcare, for example, broadband facilitates: improved quality of rural medical practices and patient care, including continuity of health services and additional medical resources; better access to specialist services; digital consultations with cost savings for patients and public health systems (decreased travel and fewer admissions); greater opportunities for practitioners to participate in professional training and development activities; and recruitment and retention of medical staff in the rural health workforce (J ang-J accard, Nepal, Alem \&Li, 2014; J ones et al., 2012; Steele \&Lo, 2013). In terms of infrastructure, most tele-health applications, such as virtual consultations, require stable high-speed connections to support real-time interactions (Steele \& Lo, 2013). Wired broadband supports these types of practices, but the fixed, wireless, mobile and satellite services in rural Australia are often too unreliable and unstable with insufficient bandwidth, particularly if affected by weather conditions, distance from towers, or bottlenecks during peak usage times (Steele \&Lo, 2013; Martin \& Rice, 2012; Tiwari et al., 2015).

There are, however, growing advantages of mobile broadband, which has proved to be an important addition to the Australian digital economy by contributing $\$ 33.8$ billion in 2013 (ACMA, 2014). Businesses that have adopted mobile broadband report quicker grouth, reduced costs, saved time, improved quality of goods/ services, increased sales, and greater access to new markets and suppliers (ACMA, 2014). Mobile broadband offers opportunities for rural communities' economic development through, for example, use of GPS and sensor data to help maximise production and distribution of agricultural goods (Griffith et al., 2013).

Advancing the availability and quality of broadband in rural areas holds promise for addressing disparities in access to essential services and socio-economic opportunities (Townsend et al., 2013). However, there are risks amid large-scale infrastructure developments of prioritising commercially compelling urban and regional centres, with other areas left behind (Middleton \&Park, 2014). Moreover, when some rural localities receive improved connectivity in the early stages of network rollout and other areas are left waiting, socio-economic divisions and digital gaps between regional areas can escalate (Alizadeh, 2013). Alizadeh's (2013) examination of ABS socio-economic and accessibility/ remoteness indexes for the 60 early release NBN sites found that infrastructure advancements can intensify existing social divisions. Regional areas with NBN access hold a competitive advantage over other localities without NBN infrastructure. Communities at the lower end of the indexes are at the greatest risk of falling further behind, particularly if scheduled in the late stages of rollout (Alizadeh, 2013). Highspeed broadband infrastructure and mobile Internet play pivotal roles in the future of the rural digital economy, as well as civic access to fundamental information and services. This article highlights the challenges faced by a rural community while waiting for improved infrastructure.

\section{Case Study Background and Methodology}

This article presents a case study of the impact of limited connectivity in Boorowa, a rural municipality located in the Southern Inlands inner regional area of New South Wales. The Southern Inlands region surrounds the nation's capital city, Canberra, and is predominantly 
agricultural land (79\%) with only $1 \%$ classified as urban (Park et al., 2015). Boorowa covers over $2,500 \mathrm{~km}^{2}$ and is located approximately $120 \mathrm{~km}$ south of the regional centre of Orange and $120 \mathrm{~km}$ north of Canberra. The council (www.boorowa.nsw.gov.au) is located in the Boorowa township, which is also home to approximately half of the municipality's 2,399 residents (ABS, 2011a). The local government area includes smaller villages such as Frogmore, Rugby, Reids Flat and Rye Park.

Like the rest of the Southern Inlands region, Boorowa is largely a farming and grazing area, with $33.5 \%$ of local employment in the agriculture, forestry and fishing industries (ABS, 2011b). Local residents also commute to Canberra (the nearest major city) and beyond for work, with the 2011 Census data showing the main categories of occupation as managers (29.9\%), labourers (15.3\%), and technicians and trades workers (12.8\%). The municipality had 341 businesses in 2011, and 167 people worked from home. The median age of Boorowa residents is 45 years (Australia's median age is 37), which is distributed over 965 households. The average household size is 2.3 persons, with a median total weekly household income of $\$ 778$. The proportion of all occupied private dwellings that had access to the Internet was $62.8 \%$ (ABS, 2011b). The region is not included in any immediate NBN plans, and connectivity is currently restricted to ADSL (digital connections through the copper telephone network) and 3G mobile coverage in some townships, as well as remote connections to the interim NBN satellite service.

This research is a follow-up project to a rural connectivity workshop that was held in Canberra in May 2014 and involved participants from seven rural New South Wales local governments (including Boorowa), the Department of Communications, Regional Development Australia, and Australia's Information and Communication Technology Research Centre of Excellence (Park et al., 2015; Freeman \& Park, 2015). This workshop sought to uncover issues faced by local authorities when seeking to expedite rural digital inclusion. The current research aimed to explore civic experiences of connectivity and its impact on local socio-economic development.

In August 2014 citizens of Boorowa were invited to participate in a structured dialogue about rural Internet connectivity. Adapting Flanagan's (2008) method, the goal was to combine the narratives from disparate individuals into a joint reflection and collaboration on priority areas necessary for development. Dialogue is encouraged so that participants openly discuss and debate ideas, develop clearer understandings of how problems affect different segments of the community, and why addressing the problems is important. The narratives that emerge through these discussions help develop a coherent and collective vision on an issue, which can be used to guide actions and promote change. It is a useful method when there are diverse stakeholders involved, if the group cannot meet regularly for ongoing discussions, or if the issue being addressed is complex (Flanagan, 2008). Two researchers and one assistant were present during the event, each of whom took notes, and the event was audio recorded and transcribed. One researcher acted as a moderator to ensure that each participant had ample opportunity to speak his/ her views and ask questions of other participants.

The Boorowa Council assisted with participant recruitment, including providing advertising space in its newsletter and identifying key community figures from different backgrounds. Among the twelve citizens who participated (Table 1), two had ADSL Internet connections at home, seven used 3G wireless connections, two used the interim satellite network, and one person had no home Internet access. The range of participants enabled broad insight into the different social and economic activities impacted by limited connectivity, and helped to uncover areas of priority for future action. 


\begin{tabular}{|l|l|l|l|}
\hline Pseudonym: & Gender: & Age: & Sector: \\
\hline Maureen & Female & $20 \mathrm{~s}$ & Public sector \\
\hline Barbara & Female & $20 \mathrm{~s}$ & Student \\
\hline Adam & Male & $30 \mathrm{~s}$ & Public sector \\
\hline Susan & Female & $30 \mathrm{~s}$ & Education \\
\hline Alicia & Female & $30 \mathrm{~s}$ & Professional \\
\hline Arthur & Male & $30 \mathrm{~s}$ & Professional \\
\hline Trevor & Male & $50 \mathrm{~s}$ & Agriculture \\
\hline Rachel & Female & $50 \mathrm{~s}$ & Student \\
\hline Winona & Female & $50 \mathrm{~s}$ & Public sector \\
\hline Carl & Male & $60 \mathrm{~s}$ & Agriculture \\
\hline Mark & Male & $60 \mathrm{~s}$ & Local business \\
\hline Louise & Female & $60 \mathrm{~s}$ & Agriculture \\
\hline
\end{tabular}

Table 1: Participants' demographic profile

Prior to the event, participants were given a 'trigger question' (the question used was: how can high-speed Internet benefit Boorowa?'). They prepared up to three responding statements, and took turns to elaborate on their ideas in group discussion on the day. In total, 33 statements were offered by the participants. All participants had the opportunity to seek further clarification of the suggestions made and contemplate the issues involved. By taking turns at the onset of the discussion, this method encouraged the transformation of participants' ideas through consideration of others' opinions. A synthesis, discussion and voting process to determine priority areas resulted in the 33 initial statements being sorted and distilled by the participants into four categories: business development; education; emergency communication; and health. These areas emerged as the key community concerns arising from the inaccessibility and unreliability of broadband in Boorowa but, according to the participants, are also where the greatest benefits from improved connectivity can be achieved.

Participants continued with more explicit discussion of the challenges and opportunities within the four categories. This enabled greater insight into their understandings, experiences and expectations of digital connectivity, and captured the everyday challenges and frustrations faced by these rural citizens. The four categories were used as the themes for analysis of the event's transcript, in addition to direct connection challenges (that is, the availability and quality of participants' Internet access). The transcript was analysed by keyword coding within these themes (without the use of analysis software) to facilitate the organisation and retrieval of the most meaningful pieces of data (Coffey \&Atkinson, 1996).

There are benefits and limitations to this research method. Some of the advantages of undertaking a qualitative approach include: gaining understanding into the experiences and perspectives of socially-situated participants (Lindlof \& Taylor, 2002) to reveal nuances that would otherwise be masked within larger quantitative datasets (Wolff \& Andrews, 2010); generating a large amount of data targeted to the research topic in a short timeframe (Morgan, 1997); and enabling comparisons between participants' viewpoints to facilitate greater insight into divergences and consistencies between the group (Flanagan, 2008; Morgan, 1997). While the dialogue included a diverse range of participants, the small sample group is by no means representative of the entire Boorowa community or reflective of all rural Australian areas. Moreover, group discussions can be unnatural social settings, which can hinder dialogue and offer less details than other methods as they rely upon group interactions to shape the data gathered (Morgan, 1997). With these limitations in mind, the research was intended only as a pilot study to identify areas impacted by rural connectivity that are in need of further in-depth research and analysis. The following section draws from participants' insights into how limited connectivity shapes their everyday experiences, and to highlight how broadband-enabled opportunities may benefit the municipality's socio-economic development. 


\section{Findings}

Participants' overarching goal was to realise improved digital connectivity in Boorowa so that local citizens would have opportunities for socio-economic advancement. As indicated above, an outcome from the research was the identification of four priority areas where development of high-speed rural broadband would bring the greatest benefits to the region: business development, education, emergency communication, and health. Table 2 details participants' statements on how improved connectivity could benefit the community within each of these themes. The table shows the level of support for each statement (participants voted for up to five priorities from among their initial statements; only those which received support are listed here). Ten of the twelve participants voted for a single statement about community safety, which suggests it is a significant point of concern. Also worth noting is that, as a category, statements relating to local business development received the most votes (23) overall, indicating that broadband access is increasingly important for rural businesses.

\begin{tabular}{|c|c|c|c|}
\hline Category: & Participants' Statements: & Votes: & $\begin{array}{l}\text { Category } \\
\text { Votes: }\end{array}$ \\
\hline \multirow{9}{*}{ Business } & To ensure economic development for the local area. & 7 & \multirow{9}{*}{23} \\
\hline & $\begin{array}{l}\text { Ability for local businesses to interact with external markets } \\
\text { and become competitive. }\end{array}$ & 5 & \\
\hline & $\begin{array}{l}\text { Better access to technology for farmers on a day-to-day } \\
\text { basis. }\end{array}$ & 2 & \\
\hline & $\begin{array}{l}\text { Better connectivity would allow opportunities for more } \\
\text { employment in a more diverse economy. }\end{array}$ & 2 & \\
\hline & Better for business, opportunities to work from home. & 2 & \\
\hline & Encourage businesses to come to Boorowa. & 2 & \\
\hline & $\begin{array}{l}\text { Being able to access essential services from remote } \\
\text { locations, leading to less travel and more efficient use of } \\
\text { time. }\end{array}$ & 1 & \\
\hline & Better mobile coverage for visitors to the town. & 1 & \\
\hline & Prospects for new and existing businesses - tourism. & 1 & \\
\hline \multirow[b]{2}{*}{ Education } & Better [general] education opportunities. & 6 & \multirow[b]{2}{*}{12} \\
\hline & $\begin{array}{l}\text { Young people having equitable access to education } \\
\text { opportunities. }\end{array}$ & 6 & \\
\hline $\begin{array}{l}\text { Emergency } \\
\text { Communication }\end{array}$ & $\begin{array}{l}\text { Community safety - effective communication with } \\
\text { ambulance and Rural Fire Service. }\end{array}$ & 10 & 10 \\
\hline Health & $\begin{array}{l}\text { Health services require high-speed Internet to communicate } \\
\text { with colleagues, patients and participate in education. }\end{array}$ & 5 & 5 \\
\hline
\end{tabular}

Table 2: Thematic categories and statements receiving participant votes

\subsection{Connection challenges: The importance of access}

Varying levels of access mean that digital gaps exist not only between rural and urban areas, but within rural regions:

We've got the dual issue here where in the town there is good access and we want that access improved up to the level of urban communities. But aside from that, we've got the 'no access at all' issue. (Adam)

Lack of, or unstable, access prevents rural citizens from capitalising on digital opportunities, even in comparison to residents in nearby townships. Improving connectivity in townships to be on par with urban speeds would be welcomed, but a matter of urgency is obtaining at least some form of Internet access for residents in more remote areas: "J ust to get better coverage in outlying areas, for mobile coverage, as well as Internet. I think we must be rated as secondclass citizens, because nothing ever happens" (Louise). Arthur noted that rural Internet does not need to be the 100mbps fibre-to-the-premises NBN once promised to urban citizens: 
So many points just come down to this digital divide and the broadband we're talking about is not the broadband the cities are talking about. We're just wanting some basic access. This idea of broadband, it's not encapsulated as one big thing.

While often associated with fibre-optics in urban spaces, the term broadband' rarely denotes fibre-optics in rural and remote areas. Instead, these citizens are referring to high-speed connections through the 3G telecommunications network and satellite technologies. There was a strong desire for additional mobile towers to be built as these would solve dual issues of poor telecommunications coverage and Internet availability in more remote areas:

They are starting to realise I think that NBN optic-fibre everywhere is not the solution, particularly when mobile solutions now are at the top rung technically; the point where it's providing as good a broadband as the cable... They should put towers up. (Arthur)

Overall, the form of connectivity was less important to participants than its capacity to enable comparable digital opportunities to their urban counterparts:

Our needs are no different from people in metropolitan centres and I certainly can't imagine anyone having a meeting like this in the middle of Canberra or the middle of Sydney about why you need these services. So I struggle with that. I think it's a little bit insulting. (Alicia)

Participants believed they should not be considered as separate to the rest of the Australian population due to their geographical location. They felt there should be a duty to ensure access to broadband - as an essential service for participation in the digital economy and potential socio-economic prosperity - regardless of location or the increased cost of establishing infrastructure in remote areas:

It's about equal opportunities. Everything in this world is online now... it's just a god given right that we should be able to access it and be able to achieve what we can, as a community, as individuals. (Winona)

The following sections explore the categories participants identified as impacted by the inaccessibility and unreliability of local broadband. Each section briefly outlines the role of connectivity in rural business, education, emergency communication and health services, respectively, before providing evidence from participants' comments of the challenges faced when trying to digitally-enable these practices in the Boorowa community. While the categories have been separated to aid analysis, the participants viewed them as interrelated and suggested that developments to any one area would bring benefits to the others.

\subsection{Business development}

Agriculture is the primary industry in the Boorowa region (ABS, 2011b). Farming is the heart of small businesses in rural Australia, although the industry has a critical skill shortage mainly due to its aging workforce (Lamb, 2012). Access to and use of digital technologies is necessary to support rural farming growth and sustainability, with innovations already used in connected areas to help ensure resilience (Lamb, 2012). Sensor networks can monitor water trough levels, yields and soil moisture/ temperature, gates can be fitted with auto alarms and (un)locking mechanisms, animals can be tracked through digital ear tags and GPS, and drones can monitor sizeable areas (Griffith et al., 2013; Lamb, 2012). However, the potential of digital technologies to contribute to Australian farming is largely unrealised, with uneven NBN developments and limited mobile telephony contributing factors (Griffith et al., 2013; Lamb, 2012). For example, mobile coverage may reach the bulk of the Australian population but it covers significantly less of the landmass (reaching approximately 25\%), and NBN plans to connect homes and businesses to fixed broadband overlooks its use in non-premised locations such as farmland (Griffith et al., 2013; Department of Communications, 2013b).

Trevor, a local farmer, noted that "day-by-day there's something new and something better and faster and quicker. I think if farmers can't keep up with what's going on in that, the rest of the world is going to go past us". Improved connectivity could offer local businesses 
opportunities to engage in wider markets and remain competitive. Without such opportunities, participants felt that future business operations may be jeopardised:

It [broadband] would increase the ability for businesses to interact with external markets. I know that a lot of market activity happens online now, particularly in the areas of auctions and that type of thing. If you're not there in the market within the last minute or two of an auction, you're going to miss out, basically. I think that's a big issue that probably already is affecting, and will have more potential in the future to affect, our community. (Adam)

Local business owners from other industries also spoke of the challenges of operating with insufficient Internet access. In particular, participants mentioned issues using government websites for taxation purposes. Without sufficient access, online taxation can be an inefficient task: "I spent four and a half hours on the Internet the other day trying to log in to get my AUSkey so I could do my tax... I must be able to save at least a couple of hours out of it" (Trevor). Rachel highlighted psychological stress and potential compliance matters arising from the compulsory use of digital taxation systems:

They [government] are the worst Internet sites ever and they're slow as all hell. I've got to do my tax stuff for our business and I'm terrified, because you can't send it in by disk anymore, that I'm not going to be able to do it by the date because we're going to have trouble with the Internet.

Given the Australian Government's recent commitment to implementing 'digital first' services by the end of 2017, there are evident challenges for individuals and businesses in rural areas trying to access such services (Freeman \& Park, 2015). Forcing small and medium enterprises to lodge their quarterly business activity statements and taxation information online does not accommodate those with barriers to connectivity.

Participants noted ways in which broadband could improve business operations including increased efficiency and competitiveness. For example, Arthur, an IT consultant, and Susan, stated that advanced connectivity would allow remote access to computers in other locations, saving time currently spent in transit and costs for clients. Rachel suggested that broadband may encourage Internet-based businesses to the area as well as improve the operations of existing businesses, such as having the capacity to sell goods online. Greater access may also encourage teleworkers to relocate to the area, particularly people who work in Canberra but seek a rural lifestyle, and only travel when necessary:

I think the ability to work from homeallows people to get involved in the higher income careers - Boorowa is sort of a low income area. So I would like to see more people on a high income, just because it would be great for the town. (Carl)

Teleworking has been shown to have monetary value for both businesses and employees, with the former saving operational costs and the latter experiencing travel gains from reduced physical attendance (Townsend et al., 2013).

Connectivity also holds promise for tourism and promotional purposes; participants suggested they could stream local events for marketing and interact with people outside of the community. As it stands, "tourists coming out are expecting to have the same access that they have [in urban centres]; to be able to be on holiday and still be able to communicate with the rest of the world" (Maureen). Boorowa's local government and business association have been attempting to obtain greater connectivity for the region for several years. Disheartened that their efforts have been unsuccessful, Winona suggested (in jest) that perhaps the local area could capitalise on its lack of connectivity:

I'vejust had an idea for economic development. We can actually say that we're the Dark Ages and you know how people get fatigued with IT stuff? They could come to Boorowa and surrounds and be disconnected from the world. 
Potential marketing prospects aside, participants believed that advanced connectivity holds value for the local economy, could offer greater opportunities for rural businesses, and contribute to sustainable regional development:

Strengthening and diversifying our economy and making sure that we're sustainable into the future. By having the better connection, it's going to allow that... diverse economy and being able to attract different industries, expanding industries and being more sustainable. (Winona)

Participants suggested that advanced communication infrastructure is central to "ensure the viability of our community in the long-term" (Alicia).

\subsection{Education}

The Internet has become a necessary part of education in Australia, and there are significant differences in digital technology use in educational settings (such as cloud computing and online lectures) and everyday life (such as social networking and emails) (Waycott, Bennett, Kennedy, Dalgarno \& Gray, 2010). Lack of digital connectivity presents a learning challenge. $\mathrm{Li}$ and Ranieri (2013) examined digital imbalances between rural and urban school children aged between 10 and 14. They concluded that rural children have fewer opportunities to access computers and the Internet at home or school, less support with new technologies, and decreased frequencies of Internet activities. They also found that lower Internet self-efficacy amongst rural students correlated directly with poor academic performance. When learnt in childhood, the capacity to use technology for independent learning forms a necessary precondition for many higher education and workplace opportunities (Katsinas \& Moeck, 2002; Townsend et al., 2013). Lack of connectivity also shapes technology integration into school learning, with tools such as electronic white boards, desktops and tablets significantly less likely to be used in rural areas (Wang, 2013).

Boorowa's local kindergarten to year 12 (K-12) school has altered its curriculum so students are not required to access the Internet from home:

My original assumption was that we had students within our local government area that were being disadvantaged by the fact that they didn't have access to the Internet and couldn't do the research that, for example, the kids in the town could - just by lack of access. What I found out was our school here actually doesn't set that expectation of students, that they will have any access at all. So it's not only the students outside of the town area. The policies of the school are structured so that everyone is equally disadvantaged, which is the way they're structuring things here in our community. But you compare that to everywhere else and we're way behind. (Adam)

Altering curriculum so students are not required to access the Internet for homework impacts children's learning development as well as their social and technical capacities (Katsinas \& Moeck, 2002). These areas are, of course, encouraged within the school; the choice to restrict options such as online assessments is something the school undertakes to ensure fair and equitable student development. The K-12 school is also considering a bring your own device' program as occurs in areas with advanced connectivity, however many participants expressed concerns that the existing network access will be inadequate to cater for this increased activity. Commenting on one of the other smaller and more remote primary schools in the region (with eight students enrolled in 2014), Alicia indicated that "they have a SMART Board at Rugby Public but they don't have [it connected to the] Internet."

All of the participants felt that local children have fewer educational opportunities than urban children and are fundamentally disadvantaged because of poor connectivity. Moreover, structuring education so that 'everyone is equally disadvantaged' may bring other long-term adverse ramifications to the region, such as hindering Boorowa's youth when entering the workforce or higher education. Winona stated:

I keep on hearing that kids who are going to Uni[versity] from Boorowa actually either are deferring or dropping out after their first year...I can't believe that they would miss 
an opportunity like that. But you start to wonder now why that's happening. Why are they not adapting?

In Boorowa's case, the comment above may be an indicative consequence from rural students' inexperience of access, technical competencies, and social development in the online context. Participants spoke of the way that higher education is rapidly changing to integrate technological advances but rural Internet infrastructure remains largely stagnant. The capacity of local infrastructure makes learning online no small feat: "Working on and downloading course materials while you're not at University... can take a very long time, which is very frustrating. Or it [the connection] will just fall out and then you've got to start again" (Rachel). Professional development opportunities are also difficult to undertake online:

We have a small number of staff who try to participate in professional development opportunities online and access to professional forums to further their knowledge. They havea lot of trouble with that because of the speed of the Internet and [they] aren't able to do it. So we therefore pay staff members to attend courses in places. It's a lot more expensive for small businesses who are trying to access professional help. (Susan)

Here, insufficient connectivity is tied with unnecessary financial expenses for rural businesses. If employers are unable to fund travel for education, then an indirect consequence is that poor Internet access contributes to the gap in rural skills. This is problematic as it is often rural citizens who require frequent and diverse re-skilling to remain viable employees in areas suffering income loss in the digital economy (Townsend et al., 2013).

\subsection{Emergency communication}

Emergency situations require effective information and communication technology integration for real-time organisation, management and coordination of mobile public safety response efforts, often across multiple governance agencies (Wamba, Edwards \& Sharma, 2012; Baldini, Karanasios, Allen \& Vergari, 2014). The New South Wales State Emergency Service, for example, equips all of its staff with smartphones in an effort to support field operations (Wamba et al., 2012). The use of digital interactive data, sensor networks, and location services aid effective information exchange, situational awareness and the coordination and mobility of response efforts. However, rural areas often lack the required bandwidth or mobile network coverage to facilitate use of necessary response tools including interactive voice and data communications (Baldini et al., 2014). Often it is the geographical terrain of rural areas that presents a challenge to effective emergency communication (NoskeTurner, Tacchi, Horst \& Papoutsaki, 2014) and limited connectivity in rural Australia has been shown to create significant delays in information-sharing regarding emergencies. Martin and Rice (2012), for example, illustrate that the lack of high-speed infrastructure between Alice Springs and Canberra has resulted in delays of more than a day in the release of emergency information, and the infrastructure that is in place is insufficiently robust to withstand adverse events. Subsequently, radio and word-of-mouth remain the most useful forms of communication during emergencies in rural areas (Ryan, 2013).

Boorowa's current network capacity presents community safety concerns, both in everyday isolated incidents and during times of crisis when emergency service communication and information is critical. Many participants were anxious about the substantial geographical areas that are not covered by either fixed broadband or mobile coverage, reporting their inability to phone for assistance from farmland and other areas outside of townships including Lachlan Valley Way, a state highway connecting the municipality to the Hume (interstate) Freeway, and noting that mobile services through providers other than Telstra often fail within the municipality's townships.

Emergency services such as the ambulance and fire brigade are often unable to be contacted (either by individuals or dispatch stations/hospitals) while en route to situations, which presents challenges both for individuals requiring assistance and service personnel:

We had a local emergency group meeting on during the week and the local ambulance rep, his biggest gripe was trouble with providing their service once they got in that dark 
[unconnected] area down to the north and the north-east...it could be a life threatening problem... [but] if there's no service [coverage] they're basically back to the basics with the ambulance service. (Trevor)

Alicia spoke of an instance when she called for an ambulance and decided it would be quicker to meet the ambulance half way between the hospital and her home. However, the ambulance was uncontactable for more than half of its 40 minute journey. Susan suggested that: "What's more concerning too is that the ambulance drivers were saying they're even having trouble with satellite phones... The satellite's getting so full that we're not even getting that now".

Trevor, who is a local captain in the Rural Fire Service (RFS), commented that the "RFS are talking about all these great systems of communication they've got now, but not many of them work in an area where you don't have mobile or Internet coverage". He indicated that the local brigade is trialling digital trackers to help identify the location of personnel during fires, with their locations synced to his iPad. But poor coverage means he can lose track of people's locations, which impedes the coordination of emergency service personnel during times of crisis. For Boorowa citizens,

It's not only the contacting in times of emergency, but it's accessing information. So okay, you know there are fires in the area, I can't get online to see what thelatest reports are or whatever, so I can't contact anyone as well. (Alicia)

Participants' comments indicated an irony surrounding current emergency communication initiatives. For example, the Australian Government has contributed \$59.5 million towards the establishment of an emergency alert system that works through both landline and mobile services (Australian Government, 2015). However, landline services in areas like Boorowa are often unreliable as repairs and upgrades to older copper networks are suspended due to anticipated NBN developments (Park et al., 2015). As Carl noted, "the copper wire's had its day. Every time it rains it does stop [working]". In terms of mobile alerts, text messages sent to residents in areas under threat are reliant upon sufficient coverage. The government acknowledges that messages will not be received if users are in areas without mobile coverage (www.emergencyalert.gov.au). Participants were frustrated that many of "the community safety issues could be solved by more phone towers" (Mark).

\subsection{Health}

Rural Australia is faced with a significant shortage in medical facilities and professionals, which results in rural citizens being admitted to hospital for preventable conditions more often than urban citizens (J ang-J accard et al., 2014). Lack of access to appropriate rural health services contributes to decreased life spans and a doubled mortality rate for rural residents under 65 years of age (J ang-J accard et al., 2014). Moreover, people living in dispersed areas often face issues of social isolation that can affect their wellbeing, which is exacerbated through poor access to communication networks (Hale et al., 2010; Townsend et al., 2013). Digital infrastructure and initiatives can offer access to services for rural populations marginalised from healthcare systems (J ones et al., 2012). Hale et al. (2010) outline four types of healthrelated practices enabled by the Internet: finding health information; accessing healthcare resources (including communication with physicians/ providers); purchasing medical/health products; and increased contact with social support networks.

Boorowa's poor connectivity inhibits basic health practices such as contact between patients, physicians and colleagues. Alicia, a medical doctor, argued:

I think [rural] health services would benefit enormously from effective mobile and Internet services, particularly to communicate with their patients. Everyone relies on mobile phones these days; it's part of our culture and the way we do things. So I think that's a big thing. Communicating with colleagues on our Internet service currently, I certainly can't even receive a CT scan via an email because it's just too big to download.

Alicia relocated to Boorowa from Sydney, and it would be difficult for her to set up a local practice to service Boorowa and its surrounds until connectivity is improved. A better 
connected local clinic would offer rural patients greater access to essential health services as well as the capacity "to be able to go to the [local] doctor and hook up with your doctor in Canberra or Sydney and they'd be able to have a conversation with all the files and that in front of them" (Barbara). In the meantime, it is common for rural patients to travel more than $100 \mathrm{~km}$ for any type of specialist advice (Adam).

Participants stated that they are unable to use information and communication technologies for social opportunities, including networking (social media), accessing entertainment (iTunes; iView), and video contact with distant family members (Skype). Susan, who has an ADSL connection, stated that, "my dad is in the States... for us to have access and be able to talk to people on the other side of the world, the software [Skype] doesn't always run so well". Local citizens using the 3G or satellite services are even less likely to be able to use Skype due to its reliance on high-speed and bandwidth. Another participant suggested that poor connectivity impacts the development of necessary social skills amongst rural youth:

A lot of our kids don't have access to the social opportunities that everyone else does... With the younger generations coming through, it becomes more noticeable - and I guess probably more acute- the effect of not having that social interaction. Most people in this room would have grown up in an environment where the way they socialise was very different. Whereas young kids now, it's completely different. (Adam)

Poor social interaction can affect mental health. Rural social and mental health services are already limited, which results in decreased help-seeking practices in rural areas $(30.8 \%$ in comparison to $36.9 \%$ in cities) and increased rates of self-harm and suicide - suicide, for example, is 66\% higher in Australian country areas than in cities (National Rural Health Alliance, 2015). While the Internet can aid access to healthcare, information, and social support, disparities in digital access in rural areas inhibit potential healthcare improvements.

\section{Discussion}

As was the case with previous communication infrastructure developments (Goggin, 2002), poor digital connectivity in rural Australia may create the emergence of a technological underclass of individuals who are left behind, with less privileged and vulnerable groups facing further marginalisation (Notara, 2011; Eardley et al., 2009). The experiences of the Boorowa community indicate the extensive socio-economic impacts that limited or no access to broadband can have in rural areas. Significant concerns have been raised in relation to the need for high-speed connectivity to stimulate rural economies through new business possibilities, address disparities in rural education and learning opportunities, prevent breakdowns in communication and information sharing during emergency situations, and empower rural citizens through improved access to health services. There was apprehension amongst participants for the long-term negative ramifications that insufficient broadband access may bring the community in these areas, such as Boorowa's youth being disadvantaged when entering higher education or the workforce.

There is an urgent need to prioritise broadband infrastructure developments for rural Australia as poor connectivity prevents many rural communities from capitalising on digital opportunities. In the few years of the NBN's existence, it has already created, reinforced and extended socio-economic disparities between those with access to it and those without (Alizadeh, 2013), and future developments could again reinforce digital disadvantages. The observations in this article therefore confirm that conditions of rurality - including the geographic and socio-economic contexts of communities - require greater consideration in planning policies (Morrison, Lane \& Hibbard, 2015; Broadband for the Bush, 2013).

To help facilitate digital opportunities in rural communities, infrastructure priority should be given to those who remain unconnected. While the Department of Communications (2013a) requested NBN Co. prioritise developments in underserved regions, the company was only required to 'consider' this request in its rollout, which can ultimately be undertaken in the most logistically and commercially feasible manner. The 2015 Regional Telecommunications 
Review Committee recommends that the rollout to areas with poor or no coverage be monitored carefully to allow informed assessment of persistent gaps and development of timely responses. For areas where deployment is less feasible, it would be beneficial to enable greater flexibility in both policy and infrastructure developments.

Localised approaches to rural digital inclusion have effectively reduced the digital divide and associated socio-economic disparities amongst marginalised and disempowered groups in other countries. For example, Walterova and Tveit's (2012) research into Europe's digital local agenda demonstrates that policy frameworks can be strategically translated to account for specific local conditions such as geographical contexts, socio-economic circumstances, and different market environments. Infrastructure developments can be tailored to suit particular areas and community needs to ensure effectiveness, but this requires policy approaches and development plans that can be adapted and targeted to the contexts of place-based communities to facilitate greater socio-economic inclusion (Hogan \&Young, 2013; Alizadeh, 2013). Such an approach privileges the development of "self-sufficient and socio-economically viable regional communities" (Hogan \& Young, 2013, p326), allowing infrastructure developments to aid the sustainability of rural locales.

There are many alternative approaches that have been proposed in this area. Amongst others, these include: the development of custom user-generated or wireless community networks (Middleton \& Bryne, 2010; Goggin, 2007); local public broadband as a civic infrastructure (McShane, 2013); extending universal service obligations to include broadband (Morsillo, 2013); increased subsidies from metropolitan areas to rural regions (Dobson, Jackson \& Gengatharen, 2011); greater public investment (Li, 2012); and public-private partnerships (Given, 2010; Falch \& Henten, 2010). The appropriateness of different forms of broadband connection will vary by locales and users.

The community participants in this research suggested that building additional mobile towers would be the most suitable for the Boorowa municipality - they would help overcome the dual issue of poor telephony coverage as well as broadband access, would be useful for both residents and visitors, and they offer decreased costs in comparison to satellite coverage. This reflects findings of the two most recent Regional Telecommunications Reviews (2012, 2015), which concluded that mobile coverage was the most pressing issue for rural Australia. Other suggestions were put forward by the participants, such as fibre-optics to nodes with copper conduits to homes or communal wireless services, but participants also recognised the limitations of these types of approaches including longer installation times, higher development and maintenance costs, and reliance upon an already failing copper network. Even with reduced speeds, mobile wireless was preferred so that all residents could benefit from some form of connectivity, and participants suggested municipal sites where additional towers would have the greatest reach. The challenge now lies in identifying the best and fastest way in which mobile towers can be built. It is here where adaptation to current policies is needed, and government intervention would be useful to encourage the development of alternative local infrastructure models and funding arrangements for rural Australia.

\section{Conclusion}

This article explores the impact of poor broadband connectivity on socio-economic opportunities in the rural municipality of Boorowa. Broadband access in rural Australia is significantly limited in terms of both availability and quality (Tiwari et al., 2015). To reiterate the point made earlier by the research participant dubbed Arthur: "thebroadband we're talking about is not the broadband the cities are talking about. We're just wanting some basic access." The Boorowa case demonstrates that divides in access exist not only between rural and urban areas but within rural regions, with connectivity discrepancies between people living in townships and those in more remote locations. Insufficient access to high-speed broadband limits Boorowa's socio-economic development, with significant short and long-term concerns in the areas of business development, education, emergency communication, and health. Local 
residents already face challenges in these areas, but they are also where the greatest benefits from improved connectivity can be realised.

Townsend et al. (2013) describe this as the paradox of rural broadband - insufficient access is a major socio-economic problem faced by rural communities but, at the same time, it is rural communities that can gain the greatest socio-economic benefits from broadband. Ironically, broadband policies often identify rural communities as exemplars for why developments are needed and who can benefit the most, while deployment is prioritised in urban spaces (Townsend et al., 2013). As digital technologies are increasingly embedded within socioeconomic practices, issues will continue to arise for those with poor connectivity. First and foremost, government resources should be directed towards providing access for disenfranchised citizens who would otherwise be unable to participate in the digital economy.

There is an urgent need for greater consideration of the conditions of rurality in NBN developments so that rural citizens are not marginalised (Alizadeh, 2013). The only way to narrow the rural-urban digital divide is to start with infrastructure developments in the most underserved regions. Privileging fibre-optic connections for large proportions of the population may fail rural communities by increasing disparities in broadband availability and quality (Townsend et al., 2013). As more everyday activities transition into online formats, rural inequities will be amplified. The participants in this research sought comparable digital opportunities to their urban counterparts so they are not disadvantaged. The government should ensure all citizens have access to essential services and can participate in the digital economy (Broadband for the Bush, 2013; Townsend et al., 2013). This will likely require strategic adaptations to current NBN policy and planning frameworks by accounting for the socio-economic contexts of rural communities to help ensure their sustainability.

\section{References}

2011- 12 Regional Telecommunications Independent Review Committee. (2012) 2011-12 Regional Telecommunications Review - Regional Communications: Empowering Digital Communities, Commonwealth of Australia, Canberra.

Alizadeh, T. (2013) "Towards the Socio-Economic Patterns of the National Broadband Network Rollout in Australia", in Ruming, K., Randolph, B. \&Gurran, N. (Eds.), State of Australian Cities Conference: Refereed Proceedings, SOAC Research Network, Sydney, http:/ / www98.griffith.edu.au/dspace/ bitstream/handle/ 10072/ 58738/90792_1.pdf?s equence $=1$

Australian Bureau of Statistics (ABS). (2011a) 2011 Census QuickStats: Boorowa, ABS, Canberra,

http:// www.censusdata.abs.gov.au/census_services/getproduct/ census/2011/ quicksta t/LGA11050?opendocument\&navpos=220

Australian Bureau of Statistics (ABS). (2011b) National Regional Profile: Boorowa (Local Government Area) 2007-2011, ABS, Canberra, http:// www.abs.gov.au/ ausstats/ abs@nrp.nsf/lookup/LGA11050Main+Features12007 $-2011$

Australian Bureau of Statistics (ABS). (2013) National Regional Profile, 2007-2011, ABS, Canberra,

http:// www.abs.gov.au/AUSSTATS/ abs@.nsf/DetailsPage/ 1379.0.55.0012007\%20to\% 202011?OpenDocument

Australian Communications and Media Authority (ACMA). (2014) The Economic Impacts of Mobile Broadband on the Australian Economy, from 2006 to 2013, Centre for International Economics, Canberra.

Australian Government. (2015) Emergency Alert, Attorney General's Department, Barton, ACT, http:// www.em.gov.au/ Emergency-Warnings/ Pages/ Emergencyalert.aspx 
Baldini, G., Karanasios, S., Allen, D. \&Vergari, F. (2014) "Survey of Wireless Communication Technologies for Public Safety", IEEE Communications Surveys \& Tutorials, 16(2):619641.

Broadband for the Bush. (2013) Better Telecommunications for Rural and Remote Australians, Desert Knowledge Australia, http://broadbandforthebush.com.au/wpcontent/ uploads/ 2013/ 05/ Broadband-for-the-Bush-Alliance-Policy-J une-2013.pdf

Coffey, A. \&Atkinson, P. (1996) Making Sense of Qualitative Data: Complementary Research Strategies, Sage, Thousand Oaks, California.

Department of Broadband, Communications and the Digital Economy (DBCDE). (2011) National Digital Economy Strategy: Leveraging the National Broadband Network to Drive Australia's Digital Productivity, DBCDE, Canberra.

Department of Communications. (2013a) Broadband Availability and Quality Report, Department of Communications, Canberra, http:// www.communications.gov.au/__data/ assets/pdf_file/ 0018/212535/ Broadband

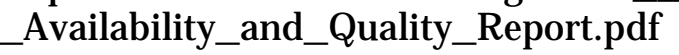

Department of Communications. (2013b) Mobile Coverage Programme - Discussion Paper, Department of Communications, Canberra, http:// www.communications.gov.au/__data/ assets/pdf_file/ 0003/204069/ Mobile_C overage_Programme_-_Discussion_Paper.pdf

Dobson, P., J ackson, P. \&Gengatharen, D. (2011) "Examining Rural Adoption of Broadband Critical Realist Perspectives", The Pacific Asia Conference on Information Systems Proceedings, AIS Electronic Library, QUT, http:/ / aisel.aisnet.org/ pacis2011/ 56

Eardley, T., Bruce, J ., \& Goggin, G. (2009) Telecommunications and Community Wellbeing: A Review of the Literature on Access and Affordability for Low-Income and Disadvantaged Groups (SPRC Report 9/09, prepared for the Telstra Low Income Measures Assessment Committee (LIMAC)), Social Policy Research Centre, University of New South Wales, Sydney.

Falch, M. \& Henten, A. (2010) "Public Private Partnerships as a Tool for Stimulating Investments in Broadband", Telecommunications Policy, 34(9):496-504.

Flanagan, T.R. (2008) "Scripting a Collaborative Narrative: An Approach for Spanning Boundaries", Design Management Review, 19(3):80-86.

Freeman, J . \& Park, S. (2015) "Rural Realities: Digital Communication Challenges for Rural Australian Local Governments", Transforming Government: People, Process and Policy, 9(4):465-479.

Given, J . (2010) 'Take Your Partners: Public Private Interplay in Australian and New Zealand Plans for Next Generation Broadband", Telecommunications Policy, 34(9):540-549.

Goggin, G. (2002) 'Rural Line of Flight: Telecommunications and Post-Metro Dreaming”, Transformations, 2:1-13.

Goggin, G. (2007) “An Australian Wireless Common?”, Media International Australia, 125:118-130

Griffith, C., Heydon, G., Lamb, D., Lefort, L.D., Taylor, K, Trotter, M. \&Wark, T. (2013) Smart Farming: Leveraging the Impact of Broadband and the Digital Economy, CSIRO and University of New England, NSW.

Hale, T.M., Cotton, S.R., Drentea, P. \& Goldner, M. (2010) "Rural-Urban Differences in General and Health-Related Internet Use", American Behavioural Scientist, 53(9):13041325.

Hogan, A. \& Young, M. (2013) "Visioning a Future for Rural and Regional Australia", Cambridge J ournal of Regions, Economy and Society, 6(2):319-330. 
J ang-J accard, J ., Nepal, S., Alem, L. \& Li, J . (2014) “Barriers for Delivering Telehealth in Rural Australia: A Review Based on Australian Trials and Studies", Telemedicineand e-Health, 20(5):496-504.

J ones, C.R., Cardoso, R.B., Hüttner, E., Oliveira, H.W., dos Santos, M.A., Lopes, M.H.I \& Russomano, T. (2012) "Towards Designing for Equity: Active Citizen Participation in EHealth", Transforming Government: People, Process and Policy, 6(4):333-344.

Katsinas, S.G. \& Moeck, P. (2002) "The Digital Divide and Rural Community Colleges: Problems and Prospects", Community College Journal of Research and Practice, 26(3):207-224.

Katz, R. \& Suter, S. (2009) Estimating the Economic Impact of the Broadband Stimulus Plan, Columbia Institute for Tele-Information, New York.

Lamb, D. (2012) "Thoughts on Capturing Opportunities and Overcoming Obstacles for Australian Agriculture Related to Electronic Agriculture", in Yunusa, I. (Ed.), Proceedings of the 16th Australian Agronomy Conference, Armidale, NSW, http:// www.regional.org.au/au/ asa/ 2012/ plenary/ 8549_lamb.htm

Li, G. (2012) 'The Return of Public Investment in Telecommunications: Assessing the Early Challenges of the National Broadband Network Policy in Australia”, Computer Law \& Security Review, 28(2):220-230.

Li, Y. \& Ranieri, M. (2013) "Educational and Social Correlates of the Digital Divide for Rural and Urban Children: A Study on Primary School Students in a Provincial City of China", Computers and Education, 60(1):197-209.

Lindlof, T.R. \& Taylor, B.C. (2002) Qualitative Communication Research Methods (2nd Edition), Sage, Thousand Oaks, California.

Martin, N. \&Rice, J . (2012) “Emergency Communications and Warning Systems: Determining Critical Capacities in the Australian Context”, Disaster Prevention and Management: An International J ournal, 21(5):529-540.

Mazzarol, T. (2015) "SMEs Engagement with E-Commerce, E-Business and E-Marketing", Small Enterprise Research, 22(1):79-90.

McShane, I. (2013) “Local Public Broadband - the Missing Link in Australia's Broadband Debate", Proceedings of the 3rd National Local Government Researchers' Forum (pp.109-119), UTS ePress, Adelaide.

Middleton, C.A. \& Bryne, A. (2011) "An Exploration of User-Generated Wireless Broadband Infrastructures in Digital Cities", Telematics and Informatics, 28(3):163-175.

Middleton, C. \& Park, S. (2014) "Waiting for the National Broadband Network: Challenges of Connectivity in Rural Australia", 20th ITS Biennial Conference - The Net and the Internet: Emerging Markets and Policy, International Telecommunications Society, Rio de J aneiro, http:/ / econstor.eu/ bitstream/ 10419/106893/ 1/ 816841047.pdf

Morgan, D.L. (1997) Focus Groups as Qualitative Research (2nd Edition), Sage, Thousand Oaks, California.

Morsillo, R. (2013) "A Shared Value Approach to Digital Inclusion", in Freeman, J. (Ed.), Proceedings of the Emerging Issues in Communication Research and Policy Conference, 2013 - Refereed Papers (pp. 1-11), News \& Media Research Centre, University of Canberra, Canberra.

Morrison, T.H., Lane, M.B. \& Hibbard, M. (2015) 'Planning, Governance and Rural Futures in Australia and the USA: Revisiting the Case for Rural Regional Planning”, J ournal of Environmental Planning and Management, 58(9):1601-1616.

National Rural Health Alliance. (2015) Mental Health in Rural and Remote Australia, National Rural Health Alliance, Deakin West, ACT, 
http:// ruralhealth.org.au/ sites/ default/ files/ publications/ fact-sheet-mental-health2015.pdf

Noske-Turner, J., Tacchi, J., Horst, H. \& Papoutsaki, E. (2014) “Locating Disaster Communication in Changing Communicative Ecologies Across the Pacific", Australian J ournal of Telecommunications and the Digital Economy, 2(4):66.1-66.16.

Notara, D. (2011) Another Barrier? Regional Consumers, Not-For-Profit Organisations, and the NBN in the Northern Rivers Region, Australian Communications Consumer Action Network, Sydney.

Park, S., Freeman, J ., Middleton, C., Allen, M., Eckermann, R. \&Everson, R. (2015) 'The MultiLayers of Digital Exclusion in Rural Australia", Proceedings of the 48th Annual Hawaii International Conference on System Sciences (pp. 3631-3640), Computer Society Press, Kauai, Hawaii.

Prieger, J.E. (2013) 'The Broadband Digital Divide and the Economic Benefits of Mobile Broadband for Rural Areas", Telecommunications Policy, 37(6-7):483-502.

Regional Telecommunications Independent Review Committee. (2015) 2015 Regional Telecommunications Review, Commonwealth of Australia, Canberra.

Ryan, B. (2013) “Information Seeking in a Flood”, Disaster Prevention and Management: An International J ournal, 22(3):229-242.

Steele, R. \&Lo, A. (2013) "Telehealth and Ubiquitous Computing for Bandwidth-Constrained Rural and Remote Areas", Personal and Ubiquitous Computing, 17(3):533-543.

Tiwari, S., Lane, M. \& Alam, K. (2015) 'The Challenges and Opportunities of Delivering Wireless High Speed Broadband Services in Rural and Remote Australia: A Case Study of Western Downs Region (WDR)", The 26 $6^{\text {th }}$ Australasian Conference on Information Systems Proceedings, University of South Australia, Adelaide, https:// acis2015.unisa.edu.au/ wp-content/ uploads/2015/11/ACIS_2015_paper_205.pdf

Townsend, L., Sathiaseelan, A., Fairhurst, G. \& Wallace, C. (2013) "Enhanced Broadband Access as a Solution to the Social and Economic Problems of the Rural Digital Divide", Local Economy, 28(6):580-595.

Walterova, I. \& Tveit, L. (2012) “Digital Local Agenda: Bridging the Digital Divide”, Transforming Government: People, Process and Policy, 8(4):345-357.

Wamba, S.F., Edwards, A. \& Sharma, R. (2012) "Big Data as a Strategic Enabler of Superior Emergency Service Management: Lessons from the New South Wales State Emergency Service", presented at Society for Information Management and MIS Quarterly Executive Pre-ICIS 2012 SIM Academic Workshop (pp. 1-3), University of Wollongong, NSW, http:// ro.uow.edu.au/ cgi/viewcontent.cgi?article=1153\&context=buspapers

Wang, P. (2013) "Examining the Digital Divide Between Rural and Urban Schools: Technology Availability, Teachers' Integration Level and Students' Perception", Journal of Curriculum and Teaching, 2(2):127-139.

Waycott, J ., Bennett, S., Kennedy, G., Dalgarno, B. \&Gray, K. (2010) “Digital Divides? Student and Staff Perceptions of Information and Communication Technologies", Computers \& Education, 54(4):1202-1211.

Wolff, R.S. \& Andrews, E. (2010) “Broadband Access, Citizen Enfranchisement, and Telecommunications Services in Rural and Remote Areas: A Report from the American Frontier", IEEE Communications Magazine, 48(5):128-135.

Copyright: (c) 2016 Freeman, Park, Middleton \& Allen. This is an open-access article distributed under the terms of the Creative Commons Attribution-NonCommercial 3.0 
Australia License, which permits non-commercial use, distribution, and reproduction in any medium, provided the original author and AJ IS are credited.

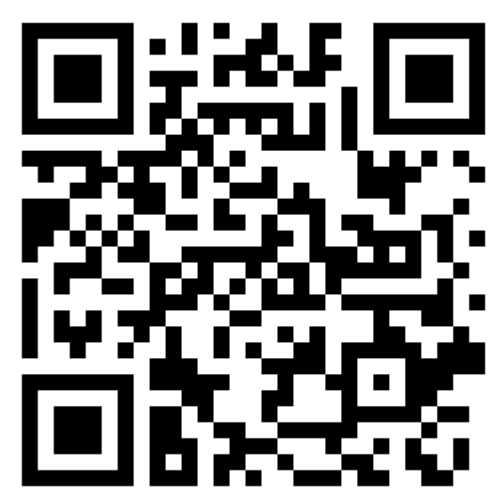

